\title{
Logistics management and supply chain management: A critical evaluation
}

\author{
Shlomo Globerson ${ }^{1}$, Gal Wolbrum ${ }^{2}$ \\ ${ }^{1}$ School of Business, Tel Aviv University, Tel Aviv, Israel, Azrieli College of Engineering, Jerusalem, Israel \\ ${ }^{2}$ Maccabi Health Care, Tel Aviv, Israel
}

Email address:

globe@post.tau.ac.il (S. Globerson)

\section{To cite this article:}

Shlomo Globerson, Gal Wolbrum. Logistics Management and Supply Chain Management: A Critical Evaluation. International Journal of Business and Economics Research. Vol. 3, No. 2, 2014, pp. 82-88. doi: 10.11648/j.ijber.20140302.15

\begin{abstract}
The purpose of this research is to identify the content of Logistics Management and Supply Chain Management, as perceived by course instructors and textbook content, and identify the core subjects of the discipline. The study is based on review and content analysis of two samples; 30 syllabi used for teaching a basic course, and 10 textbooks that are dedicated to the discipline. A list of belonging subjects was identified, importance for each subject was estimated, and the level of agreement between the syllabi and the textbook samples was evaluated. Results identified 27 relevant subjects, of which eight were identified as "core subjects". The core subjects are: Information and technology, Inventory, Overview and concepts, Transportation and conveying, Logistics flow, Facility location, Customer service, and Performance measurement. There is a high level of agreement within each sample and between the two samples, with regard to the relative importance of the identified subjects. The above results support an agreed framework for a Logistics Management course, which becomes a common one in different management programs.
\end{abstract}

Keywords: Logistics Management, Supply Chain Management, Content Analysis, Syllabus

\section{Introduction}

The "Scientific Management" movement, initiated by Taylor (1911), was probably the start of recognizing "Management" as a scientific discipline. The body of knowledge included in "management" has been drastically changed since its initiation. Its original emphasis was at first on developing areas such as "method improvement," "work measurement" and "wage incentives". Later it expended into other areas such as "industrial psychology," "quality" and "marketing".

The dynamic nature of the body of knowledge of each discipline is such that it expands over time, into new areas. Some of those areas develop later to an extent that they become academic disciplines by themselves. For example, "Industrial Engineering" was once an area within the "Management" discipline, but it grew into its own discipline. Or "Project Management" was an area within "Industrial Engineering" and also became a separate discipline.

"Logistics Management" (LM) also followed a suit, similar to the above two disciplines. There are different definitions for LM scope, of which the following is a good example: "Logistics is that part of the supply chain process that plans, implements, and controls the efficient, and effective flow and storage of goods, services, and related information from the point-of-origin to the point-of-consumption, in order to meet customers' requirements" (Stock \& Lambert, 2001). CSCMP - the Council of Supply Chain Management Professionals, relates to the relationship between LM and Supply Chain Management (SCM). It states that "LM is that part of SCM that plans, implements, and controls the efficient flow and storage of goods, services and related information between the point of origin and the point of consumption in order to meet customers' requirements".

Although LM is a part of SCM, it was not always so since SCM was introduced into the logistics life cycle only in a late stage, as described by the following paragraphs, describing its historical development.

The roots of logistics thought originated around farm-to-market economics, and was first documented around the early 1900s. A review of the development of logistics can be found in Kent and Flint (1997). The evolution of logistics thought appears to fall into the following seven eras:

Era 1: Farm to market, starting around 1900 's, in which 
the main focus was on transportation and distribution.

Era 2: Military and business, starting during the Second World War. Needs generated by the war gave a push to the development of functions such as transportation, warehousing, inventory and physical distribution.

Era 3: Integration of functions, started around 1960, focusing on the total system's performance, rather than on performance of individual functions. Logistics started to be taught as an area.

Era 4: Customer focus, starting around 1970, where customer service was regarded as the primary focus of the company.

Era 5: Logistics strategy, starting during the 1980s, where it has been considered as a critical component in the company's strategy. Emerging concepts are such as SCM, environmental logistics, reverse logistics, and a heightened awareness of globalization. Information technology as well as strategy concepts have had a significant influence.

Era 6: Integrated SCM, starting during the 1990s, where logistics processes are extended to the companies involved across the supply chains. It requires greater involvement with many functional areas within the organizations involved

Era 7: International SCM, starting around 2000, where the chain crosses countries' borders, mostly due to the existence of very effective information technologies.

Academia continuously struggles with the content identification of logistics courses, wishing to support industry's needs. As expressed by Gravier and Farris (2008), articles about logistics education had progressed from asking, "Who are we?" in the 1960s and 1970s, to asking "What are we teaching?" from the 1980s. They also point out that two-thirds of the way into the first decade of the 2000s, the number of published articles that address logistics education, is greater than in any two consecutive previous decades, evidence for its growing importance. The debate concerning the content of a logistics course will always be around since practitioners' needs are dynamic.

Murphy and Poist's (1998) study, divided the skills required for proper functioning of high level logistics professional into three areas: management skills, business skills, and logistics skills. Within each skill they evaluated the subjects' importance. For example, subjects of high importance within management skills were: organizing, planning, and problem solving. Within business skills: human skills, business writing and information systems, and within logistics: customer service, traffic and transportation, inventory control and warehousing. For proper functioning as a logistics manager, one should acquire abilities belonging to the three areas, although in different intensities. For example, Gravier and Farris (2008) quote recent studies that show the great importance of information systems, to logistics. Another study, conducted by Van Hoek (2001), identified the four highest ranking of general logistics topics as: integration of information, inventory management, cross functional coordination and reconfiguration of SCM. The last study also ranks the importance of a list of 24 specific logistics topics. Within this list, the four highest ranking topics are: quality management, performance measurement, warehouse management and material handling

A major change in logistics took place when the concept of SCM was introduced. The Supply Chain Council at The Ohio State University argued that SCM is more comprehensive than Logistics, encompassing the management of multiple business processes (including logistics processes) and involves frequent information updating among supply chain members for effective SCM (Cooper, Lambert and Pagh, 1997). Their model suggests that SCM involves the management of eight business processes; two of which, Customer Relationship Management (CRM) and Supplier Relationship Management (SRM), form critical links across the supply chain. The other six processes (Customer service management, Demand management, Order fulfillment, Manufacturing, Flow management, product development and commercialization, and Returns management) are coordinated through SRM and CRM.

SCM is defined by CSCMP as "an integrating function with primary responsibility for linking major business functions and business processes within and across companies into a cohesive and high-performing business model. It includes all of the LM activities noted above, as well as manufacturing operations, and it drives coordination of processes and activities with and across marketing, sales, product design, finance, and information technology. Using the above definitions, it becomes clear that SCM has a broader perspective and it requires overall managerial efforts throughout all organizational functions, of the organizations involved. Therefore, a course that covers SCM should first cover LM subjects, followed by other subjects of which a few are from other managerial disciplines, such as marketing and finance. There is ambiguity concerning the boundaries of SCM due to the parts of the supply chain that are external to LM, since it deals with integration of activities of different functional departments among all companies that play a part in the supply chain (e.g. Arlbjom \& Halldorsson, 2002; Van Hoek, 2001). Therefore, from now on the paper will refer to the LM and SCM as an LM/SCM discipline.

A widely discussed issue with regard to $\mathrm{LM} / \mathrm{SCM}$ is whether it is a discipline. According to "Wikipedia.org", an area is matured into an academic discipline when it is taught and researched at a university level, has its own journals, and has dedicated professional associations. LM/SCM fulfills the above criteria since there are universities that offer a degree in $\mathrm{LM}$ or SCM, as can be traced via the internet; there are journals dedicated to the subject (e.g. IJLM - International Journal of Logistics Management, IJPDLM - International Journal of Physical Distribution \& Logistics Management, JBL - Journal of Business Logistics) in which researchers publish their studies' results, and there are also associations of which LM/SCM is their major interest (e.g. CSCMP - Council of Supply Chain Management Professionals). There is still a debate with regard to the extent of the maturity of the 
discipline, as discussed later. However, a further comprehensive analysis of Hartland et al (2006) concerning the criteria for an area to become a discipline, arrived at the conclusion that SCM may be categorized as an emerging discipline and has not matured yet.

An effective vehicle to accelerate discipline maturity is to structure its content, as expressed by its basic courses. There are few articles that deal with the desired content and context of LM /SCM (e.g. Stock, 1997), but neither concentrated on capturing its content, as expressed by relevant professionals, which is the purpose of this study.

Since there is ambiguity concerning the differences between LM and SCM, and since LM is a major part of SCM, it was decided to collect information about both. Two possible approaches for identifying the content of an academic body of knowledge have been traced in the literature, syllabi content and textbook content analysis. Drisko (2008) analyzed syllabi to capture the variations and commonalities among instructors who teach a "qualitative research" course. Variations were manifested via the numbers of course sessions, focal content, readings, and assignments. Few syllabi included named qualitative research approaches. Further, very few assignments addressed qualitative research content. In his conclusion Drisko calls for identifying core content, as the lowest common denominator for all syllabi representing the same body of knowledge. Syllabi analysis is a very powerful tool to explore course content variation. For example, Stephens and O'Hara (2001) have studied the content of a basic Information Technology course offered in every Business school and have found a wide variation as well.

Campbell and Collins (2007) reviewed textbooks content to identify topics contained and determine the extent of agreement among authors, regarding the essential nature of topics within and across the discipline. Many of the topics identified were consistent with traditional assessment expectations of general and special education environments, while other, arguably important topics, were not identified as essential. The idea of core assessment topics for all teachers is introduced in this research as well.

A picture of a similar pattern with regard to content variation is also found on the curriculum level of a discipline. For example, Pyster, Turner, Henry, Laster and Bernstein (2009) reviewed the curriculum for the software engineering disciplines in 28 universities. They found that there are significant differences among them, even with regard to the required (versus the elective) courses.

The above two sources, course syllabi and textbooks, were selected for data collection. It is expected that there will be content differences among instructors who teach the same course, resulting from factors such as "academic freedom" and "discipline's maturity." Academic freedom allows instructors to establish content of syllabi, according to their perception of the subject matter. In some cases there may exist a structured syllabi, dictated by the department to which the instructor belongs to. For example, well established disciplines such as mathematics and physics.
This is not the case with disciplines such as "project management" and LM/SCM, since they are not as matured. Therefore, one can expect wide content variations among syllabi used by instructors who teach them. The content of textbooks is even less structured since authors include in the book whatever they consider important.

\section{The Present Study}

\subsection{Research Purpose and Research Goals}

As stated before, the objective of the study is to capture the perception of professionals concerning the present content of SCM, and LM in particular. In accordance with the literature finding cited above, we assume that the perceived content can be captured via two major sources: content of syllabi of basic courses taught by either LM or SCM instructors, and textbooks. Both, an instructor of a course and an author of a textbook, are not guided by restricted rules that they should follow when generating the content. Therefore, content variation within and between the two is expected, and it is also of interest to explore the differences between the two sources.

The following are the research goals:

1. To determine the extent of agreement, concerning LM/SCM basic content among instructors - to identify which subjects are repeatedly taught in LM/SCM basic courses.

2. To determine the extent of agreement, concerning LM/SCM content among authors - to identify which subjects repeatedly appear in LM/SCM textbooks.

3. To determine the extent of agreement, concerning LM/SCM content, between instructors and authors - to identify whether the common subjects of basic courses are the common subjects in textbooks.

4. Identifying the common core of subjects.

These goals will be explored via the analysis of the collected data.

\subsection{Data Collection}

The syllabi sample includes the review of 30 courses' syllabi at academic institutes around the world. Syllabi were identified via the internet, using the following phrases: "logistics management syllabus," "introduction to logistics management syllabus," "supply chain management syllabus," "introduction to supply chain management syllabus." Criteria used for including syllabi in the sample were as follows:

1. The course should deal with LM/SCM in general and not just a specific subject (e.g. inventory, transportation, production).

2. The syllabus should be detailed and specify at least five different subjects.

3. The syllabus should specify the academic institute within which the course is studied.

4. The course should be taught after the year 2000 .

30 Syllabi that met the above criteria, were included in 
the sample.

The textbook sample includes the review of ten textbooks. Criteria used for selecting textbooks for the sample were as follows:

a. The textbook should deal with $\mathrm{LM} / \mathrm{SCM}$ in general and not just specific subjects within it.

b. The textbook should refer to at least five different subjects.

c. A textbook should not be selected if it's author is also an instructor for a syllabi included in the syllabi sample defined above.

The 10 textbooks that met the above criteria, were included in the sample. They are listed in the Appendix, appeared right after the Reference list.

A typical syllabus, lists subjects taught but does not specify the amount of time spent on each. Therefore, there is no indicator concerning the depth to which each subject is taught. This is not the case when dealing with a textbook, since the number of pages dedicated to a subject, may serve as an indicator of the perceived importance by the author, on that subject. While the syllabi study shows only the percentage of syllabi that cover each subject, the textbook study shows both, the percentage of textbooks that cover each subject and the average percent of pages dedicated to it (depth of the coverage of each single subject).

The following sections summarize the data collected. Since not all the textbooks use the same semantics for all the subjects, we grouped subjects according to their general meaning and created 27 categories of content items.

\section{Data Analysis}

\subsection{The Extent of Agreement, Concerning LM/SCM Content, among Instructors}

Table 1 presents the content distribution of the sample of 30 syllabi. For the purpose of comparison between the syllabi sample and the textbook sample, the list of subjects in Table 1 also includes "safety and security" although it does not appear in either of the syllabi.

There are a few subjects (the core subjects) that are more common than others. Let us define "core subjects" as those which are taught by $70 \%$ and more, of the instructors.

Table 1. Percent of Subjects included in syllabi, for introductory LM/SCM course.

\begin{tabular}{ll}
\hline subject & $\mathbf{\%}$ \\
\hline Overview and concepts & 83 \\
Importance & 23 \\
Logistics and Competitiveness & 33 \\
Global logistics & 47 \\
Logistics flow & 57 \\
Performance measurement & 37 \\
Information and technology & 73 \\
Customer service & 63 \\
Demand forecasting & 43 \\
Distribution & 47 \\
Transportation and conveying & 70 \\
\hline
\end{tabular}

\begin{tabular}{ll}
\hline subject & \% \\
\hline Inventory & 97 \\
Storage and warehouse & 57 \\
Packaging & 23 \\
Facility location & 77 \\
Procurement and delivery & 53 \\
Material handling & 30 \\
Production of goods \& services & 10 \\
Strategy \& future challenge & 23 \\
Benchmarking & 3 \\
Managing the logistics organization & 57 \\
Planning the logistic system & 43 \\
Costing & 20 \\
Import \& export & 3 \\
Safety and security & 0 \\
Environmental protection & 13 \\
Decision support systems & 10 \\
\hline
\end{tabular}

Therefore, the core subjects are Inventory (97\%), Overview and concepts (83\%), Facility location (77\%), Information and technology (73\%) and Transportation and conveying $(70 \%)$. Some of the subjects, such as the core subject "Information and technology", were not developed purposely for LM/SCM and were emigrated from other disciplines. Due to the discipline trend of system integration, they are included as relevant subjects within the discipline. Although "overview and concepts" is considered to be a core subject, it is not a real one since it covers different aspects of the discipline. However, it is an essential subject in teaching any type of course.

The syllabi included in the sample, had different titles. One major group includes syllabi in which "Logistics Management" was part of the syllabus title, where the other group includes those which "Supply Chain Management" was part of their titles. Table 2 compares the content of the two groups. From Table 2, evidence concerning the level of agreement between their content, is emerging: the correlation between "\% LM syllabi" and "\% SCM syllabi" was $0.67(\mathrm{p}<0.01)$.

It seems that syllabi of LM concentrate more on the micro level of logistics as can be seen from the score of subjects such as "storage and warehouse," whereas syllabi of SCM concentrate more on macro level such as "logistics flow," and "managing the logistics organization." However, it is important to note that most subjects appear in both, although with a different percentage.

Table 2. Extent of agreement concerning subjects importance, in LM and SCM syllabi.

\begin{tabular}{lcc}
\hline subject & \% LM & \% SCM \\
\hline Overview and concepts & 93 & 73 \\
Importance & 7 & 0 \\
Logistics and Competitiveness & 29 & 36 \\
Global logistics & 43 & 55 \\
Logistics flow & 43 & 73 \\
Performance measurement & 36 & 45 \\
\hline
\end{tabular}




\begin{tabular}{lcc}
\hline subject & \% LM & \% SCM \\
\hline Information and technology & 86 & 82 \\
Customer service & 71 & 45 \\
Demand forecasting & 43 & 45 \\
Distribution & 29 & 73 \\
Transportation and conveying & 100 & 36 \\
Inventory & 93 & 100 \\
Storage and warehouse & 79 & 27 \\
Packaging & 29 & 18 \\
Facility location & 79 & 73 \\
Procurement and delivery & 64 & 55 \\
Material handling & 36 & 18 \\
Production of goods \& services & 7 & 18 \\
Strategy \& future challenge & 21 & 18 \\
Benchmarking & 0 & 0 \\
Managing the logistics org. & 43 & 82 \\
Planning the logistic system & 21 & 64 \\
Costing & 7 & 36 \\
Import \& export & 0 & 9 \\
Safety and security & 0 & 0 \\
Environmental protection & 14 & 9 \\
Decision support systems & 0 & 18 \\
\hline
\end{tabular}

\subsection{The Extent of Agreement, Concerning LM/SCM Content, among Authors}

The second sample includes 10 relevant textbooks. Table 3 specifies the average percentage of pages dedicated to each subject (\%pg), which is an indicator for subjects' depth of coverage. And "\%bk" means the percentage of books that cover this subject.

Using the same criterion as in the previous section, core subjects are defined as those that are covered by at least $70 \%$ of the books. Eight core subjects were identified in the textbook sample. Those subjects are Information and technology (100\%), Logistics flow $(90 \%)$, Overview and concepts (80\%), Performance measurement (80\%), Transportation and conveying (80\%), Customer service (70\%), Inventory (70\%) and Strategy \& future challenges (70\%).

One may expect that the higher the perception of subject's importance is, the larger should be its depth of coverage. For investigating this hypothesis, we calculated the correlation between "\%bk" and "\%pg", which came to as high as 0.85 $(p<0.01)$. This high correlation means that the higher the exposure rate of a subject within the textbooks (\%bk), the greater is its depth of coverage (\%pg").

One of the issues analyzed on the syllabi sample, was the difference between LM and SCM. Although the textbook sample is small, it is of value to further explore the issue in order to see if the same finding is consistent. Out of the ten textbooks, three use LM as part of their title, three use SCM and four use a combination of both. The fact that four out of the ten books have both LM and SCM in their titles, point out the strong relationship between the two and the difficulties of differentiating between their content. Table 4 presents the content of the first two groups of textbooks.

Table 3. Extent of inclusion of subjects in LM/SCM textbooks.

\begin{tabular}{lll}
\hline subject & $\mathbf{\% p g}$ & $\mathbf{\% b} \mathbf{k}$ \\
\hline Overview and concepts & 5.5 & 80 \\
Importance & 1.8 & 40 \\
Logistics and competitiveness & 4.8 & 40 \\
Global logistics & 5.5 & 60 \\
Logistics flow & 6.5 & 90 \\
Performance measurement & 5.7 & 80 \\
Information and technology & 9.5 & 100 \\
Customer service & 7.0 & 70 \\
Demand forecasting & 0.6 & 20 \\
Distribution & 1.5 & 40 \\
Transportation and conveying & 12.1 & 80 \\
Inventory & 5.8 & 70 \\
Storage and warehouse & 5.2 & 60 \\
Packaging & 1.1 & 50 \\
Facility location & 2.7 & 60 \\
Procurement and delivery & 2.9 & 50 \\
Material handling & 0.7 & 30 \\
Production of goods \& services & 2.8 & 50 \\
Strategy \& future challenges & 4.9 & 70 \\
Benchmarking & 1.2 & 30 \\
Managing the logistics org. & 3.3 & 40 \\
Planning the logistic system & 5.1 & 60 \\
Costing & 0.2 & 20 \\
Import \& export & 2.1 & 10 \\
Safety and security & 0.3 & 10 \\
Environmental protection & 0.3 & 10 \\
Decision support systems & 1.0 & 10 \\
\hline & & \\
& & \\
& &
\end{tabular}

From the data presented in Table 4, one can trace the following, which is consistent with the observation of similar analysis with the syllabi sample: Textbooks of LM seem to concentrate more on the micro level of logistics as can be seen from subjects such as "storage and warehouse," whereas textbooks of SCM seem to concentrate more on the macro level such as "logistics flow." No correlation was found between "\%PG LM books" and "\% PG SCM books" $(\mathrm{R}=0.06, \mathrm{NS})$.

Table 4. Subjects included in LM and SCM books.

\begin{tabular}{lllll}
\hline \multirow{2}{*}{ subject } & \%pg & & \%bk & \\
& LM & SCM & LM & SCM \\
& Bks & Bks & Bks & Bks \\
\hline Overview and concepts & 2.7 & 10.2 & 67 & 100 \\
Importance & 0.9 & 0 & 33 & 0 \\
Logistics and competitiveness & 3.5 & 8.4 & 67 & 33 \\
Global logistics & 8.8 & 2.6 & 67 & 33 \\
Logistics flow & 2.7 & 13.6 & 67 & 100 \\
Performance Measurement & 3.5 & 5.7 & 67 & 67 \\
Information and technology & 9.0 & 15.0 & 100 & 100 \\
Customer service & 3.3 & 5.3 & 67 & 33 \\
Demand forecasting & 0 & 0 & 0 & 0 \\
Distribution & 1.9 & 1.5 & 67 & 33 \\
Transport. and conveying & 23.6 & 2.3 & 100 & 33 \\
Inventory & 6.8 & 3.4 & 100 & 33 \\
Storage and warehouse & 12.4 & 0 & 100 & 0 \\
Packaging & 1.6 & 0 & 67 & 0 \\
Facility location & 1.6 & 2.8 & 33 & 33 \\
Procurement and delivery & 2.5 & 3.8 & 67 & 33 \\
\hline
\end{tabular}




\begin{tabular}{|c|c|c|c|c|}
\hline subject & $\begin{array}{l}\text { \%pg } \\
\text { LM } \\
\text { Bks }\end{array}$ & $\begin{array}{l}\text { SCM } \\
\text { Bks }\end{array}$ & $\begin{array}{l}\text { \%bk } \\
\text { LM } \\
\text { Bks }\end{array}$ & $\begin{array}{l}\text { SCM } \\
\text { Bks }\end{array}$ \\
\hline Material handling & 0.3 & 0 & 33 & 0 \\
\hline Production of gds \& services & 0.5 & 6.0 & 33 & 67 \\
\hline Strategy \& future challenges & 1.0 & 9.1 & 33 & 67 \\
\hline Benchmarking & 1.1 & 0 & 33 & 0 \\
\hline Managing the logistics org. & 2.1 & 0 & 33 & 0 \\
\hline Planning the logistic system & 1.5 & 6.9 & 67 & 67 \\
\hline Costing & 0 & 0 & 0 & 0 \\
\hline Import \& export & 7.0 & 0 & 33 & 0 \\
\hline Safety and security & 0.9 & 0 & 33 & 0 \\
\hline Environmental protection & 1.1 & 0 & 33 & 0 \\
\hline Decision support system & 0 & 3.3 & 0 & 33 \\
\hline
\end{tabular}

\subsection{The Extent of Agreement between Instructors and Authors}

Since the two samples of syllabi and textbooks relate to the same list of subjects, it enables to compare their results, as presented by Table 5. The subjects' list in Table 5 is arranged in descending order of the average (Avg) score $((\% \mathrm{~S}+\% \mathrm{~B}) / 2)$. The following are ranked as the first eight subjects: Information and technology, Inventory, Overview and concepts, Transportation and conveying, Logistics flow, Facility location, Customer service, and Performance measurement.

The correlation between the two groups with regard to the percentage of subjects' exposure, has reached $0.73(\mathrm{p}<0.01)$, which statistically supports the high level of agreement between the two groups concerning the subjects.

No other study of identical structure was administered. Therefore, it is impossible to compare the results of this study to others. A study of some similarities to the present one was administered by Van Hoek (2001). Via a market survey he ranked the relative importance of logistics' subjects by generating two different categories, general logistics subjects and subjects of specific nature.

The seven general logistics subjects obtained the highest score, in Van Hoek's study were: Internal integration of information flow, Inventory management, Cross functional coordination, Reconfiguration of supply chain, External integration of information flow, Outsourcing and Globalization of transport. The subjects of specific logistics nature were Quality management, Performance measurement, Warehouse management, Material management, Bar coding and data scanning, Order receiving and fulfillment, Warehouse design, and Reverse logistics. Although the names of some of the subjects are different, similarities between Van Hoek's lists and the one generated by this study is recognized.

From the above discussion, we may conclude the following:

1. The high correlation between the average percentages that subjects were reviewed by syllabi $(\% \mathrm{~S})$ and the textbooks $(\% \mathrm{~B})$, is evidence that a common logistics subjects' list, is emerging.

2. There is a need to better identify the general management subjects which are of importance to LM/SCM. For example, the subject "Strategy \& future challenges," which reached just 23 within the syllabi group, obtained as high as 70 within the textbook group.

3 . There is a need to formally map the body of knowledge of LM/SCM in a manner similar to the mapping of Project Management BOdy of Knowledge (PMBOK), see Project Management Institute (2008).

Table 5. Average percentage that subjects were reviewed either in syllabi $(\% \mathrm{~S})$ or in textbooks $(\% B)$, arranged in descending order of the averag.

\begin{tabular}{|c|c|c|c|}
\hline subject & $\% \mathrm{~S}$ & $\% \mathrm{~B}$ & Avg \\
\hline Information and technology & 73 & 100 & 86 \\
\hline Inventory & 97 & 70 & 83 \\
\hline Overview and concepts & 83 & 80 & 81 \\
\hline Transportation and conveying & 70 & 80 & 75 \\
\hline Logistics flow & 57 & 90 & 73 \\
\hline Facility location & 77 & 60 & 68 \\
\hline Customer service & 63 & 70 & 66 \\
\hline Performance measurement & 37 & 80 & 58 \\
\hline Storage and warehouse & 57 & 60 & 58 \\
\hline Global logistics & 47 & 60 & 53 \\
\hline Procurement and delivery & 53 & 50 & 51 \\
\hline Planning the logistic system & 43 & 60 & 51 \\
\hline Managing the logistics organization & 57 & 40 & 48 \\
\hline Strategy \& future challenges & 23 & 70 & 46 \\
\hline Distribution & 47 & 40 & 43 \\
\hline Logistics and competitiveness & 33 & 40 & 36 \\
\hline Packaging & 23 & 50 & 36 \\
\hline Importance & 23 & 40 & 31 \\
\hline Demand forecasting & 43 & 20 & 31 \\
\hline Material handling & 30 & 30 & 31 \\
\hline Production of goods \& services & 10 & 50 & 30 \\
\hline Costing & 20 & 20 & 20 \\
\hline Benchmarking & 3 & 30 & 16 \\
\hline Environmental protection & 13 & 10 & 11 \\
\hline Decision support system & 10 & 10 & 10 \\
\hline Import \& export & 3 & 10 & 6 \\
\hline Safety and security & 0 & 10 & 5 \\
\hline
\end{tabular}

\subsection{Designing an Introductory Course}

The present study may be used as an aid for course outline. For example, an introductory course of either LM/SCM should include core subjects as well as other subjects. The following may be used as a list of criteria to support the decision concerning the selected subjects:

1. Importance of subjects, as stated by Table 5

2. Departmental orientation with regard to the direction of the discipline

3. Instructor's preferences and abilities

4. Uniqueness to the discipline. For example, "Logistics flow" and "Facility location" are mostly relevant to LM/SCM where a subject such as "Performance measurement" is relevant to all other disciplines as well.

5. Course boundaries. For example, subjects such as "Global logistics and "Import \& export", are needed only when the course is tailored to participants who are expected to be exposed to global interaction.

\section{Conclusion}

Although $\mathrm{LM} / \mathrm{SCM}$ is a relatively new academic 
discipline, there is a high level of agreement concerning its content, within those who teach it, within those who authored textbooks in the discipline, and between the two groups. The identification of the eight LM/SCM core subjects help to clarify the core content of the discipline.

In spite of the similarities among of LM/SCM subjects listed in either syllabi or textbooks, there are significant differences as well. The existence of those differences point out to the need to formally map the body of knowledge of $\mathrm{LM} / \mathrm{SCM}$, in a manner similar to the mapping existed in other disciplines, such as Project Management.

There is also some evidence that syllabi of LM concentrate more on the micro level of logistics such as "storage and warehouse," whereas syllabi of SCM concentrate more on macro level such as "logistics flow," and "managing the logistics organization." However, in spite of the differences between the two, they highly resemble to each other.

Finally, the discipline deals with integration of many organizational facets, such as "performance measurement" and "costing" which should be imported from other disciplines. Therefore, successful training of LM/CSM requires also a proper integration of relevant subjects coming from other disciplines

\section{References}

[1] Arlbjom, J.S. \& Halldorsson, A. (2002). Logistics knowledge creation: Reflections on content, context and processes. International Journal of Physical Distribution and Logistics Management, 32 (1), 22-40.

[2] Campbell, C. \& Collins, V. (2007). Identifying essential topics in general and special education introductory assessment textbooks. Educational Measurement: Issues and Practice. 26 (1), 9-18.

[3] Cooper, M.C., Lambert, D.M. \& Pagh, J.D. (1997). Supply chain management: More than a new name for logistics. International Journal of Logistics Management, 8 (1), 1-14.

[4] Drisko, J.W. (2008). How is qualitative research taught at the master's level. Journal of Social Work Education, 44 (1), 85-101.

[5] Gravier, M.J. \& Farris, M.T. (2008). An analysis of logistics pedagogical literature: Past and future trends in curriculum, content and pedagogy. International Journal of Logistics Management, 19 (2), 233-253.

[6] Harland, C.M., Lamming, R.C., Walker, H., Phillips, W.E., Caldwell, N.D., Johnsen, T.E., Knight, L.A. \& Zheng, J. (2006). Supply management: Is it a discipline? International Journal of Operations and Production Management, 26 (7), 730-753.

[7] Kent, J.L. \& Flint, D.J. (1997). Perspectives on the evolution of logistics thought. Journal of Business Logistics, 18 (2), $15-30$.
[8] Murphy, P.R. \& Poist, R.F. (1998). Skill requirements of senior-level logisticians: Practitioner perspectives. International Journal of Physical Distribution and Logistics Management, 28, (4), 284-301.

[9] Project Management Institute (2008). A Guide to Project Management Body of Knowledge (PMBOK). 4th edition. Project Management Institute, Inc.

[10] Pyster, A., Turner, R., Henry, D., Laster, K. \& Bernstein, L. (2009). Master's degrees in software engineering: An analysis of 28 university programs. IEEE Software, 26 (5), 94-101.

[11] Stephens, C. \& O'Hara, M. (2001). The core information technology course at AACSB-accredited schools: Consistency or chaos? Journal of Education for Business, 76 (4), 181-185.

[12] Stock, J.R. (1997). Applying theories from other disciplines to logistics. International Journal of Physical Distribution and Logistics Management, 27 (9-10), 513-539.

[13] Stock, J.R. \& Lambert, D.M. (2001). Strategic Logistics Management. McGraw-Hill: Boston, MA.

[14] Taylor, F.W. (1911). The Principles of Scientific Management. Harper Brothers: New York.

[15] Van Hoek, R.I. (2001). Logistics education: Achieving market and research driven skill development. International Journal of Physical Distribution and Logistics Management, 31 (7-8), 505-519.

[16] Hugos, M. (2006). Essentials of supply chain management. John Wiley \& Sons: New Jersey.

[17] Rushton, A., Croucher, P. \& Baker, P. (2006). The handbook of logistics and distribution management. Kogan Page Limited: London.

[18] Stroh, M.B. (2006). A practical guide to transportation and logistics. Logistics Network Inc: New Jersey.

[19] Langley, C.J., Coyle, J.J., Gibson, B.J., Novack, R.A. \& Bardi, E.J. (2003). Managing supply chains: A logistics approach. South-Western, USA.

[20] Bowersox, D.J., Closs, D.J. \& Cooper, M.B. (2002). Supply chain logistical management. McGraw-Hill: New York.

[21] Vogt, J.J., Pienaar, W.J. \& de Wit, P.W.C. (2002). Business Logistics Management: Theory and Practice. Oxford University Press: South Africa.

[22] Simchi-Levi, D., Kaminsky, P. \& Simchi-Levi, E. (2000). Designing and managing the supply chain: Concepts, strategies and case studies. McGraw-Hill: Boston, MA.

[23] Handfield, R.B. \& Nichols, E.L. (1999). Introduction to supply chain management. Prentice Hall: New Jersey.

[24] Christopher, M. (1998). Logistics and supply chain management - Strategies for reducing cost and improving service. Pearson Education Limited: Edinburgh.

[25] Bowersox, D.J. \& Closs, D.J. (1996). Logistical management: The integrated supply chain process. McGraw-Hill: New York. 